\title{
Population genetic structure of Asiatic Hard Clam (Meretrix meretrix) in Thailand based on Cytochrome Oxidase subunit I gene sequence
}

\author{
VERAKIAT SUPMEE ${ }^{1}$, PRADIT SANGTHONG ${ }^{2}$, APIRAK SONGRAK ${ }^{3}$, JUTHAMAS SUPPAPAN ${ }^{4, \bullet}$ \\ ${ }^{1}$ Department of Science, Faculty of Science and Technology, Rajamangala University of Technology Srivijaya. Nakhon Si Thammarat, 80110, Thailand \\ ${ }^{2}$ Department of Genetics, Faculty of Science, Kasetsart University. Bangkok, 10900, Thailand \\ ${ }^{3}$ Department of Fishery Technology, Faculty of Science and Fishery Technology, Rajamangala University of Technology Srivijaya. Trang, 92150, \\ Thailand \\ ${ }^{4}$ Education in Science Graduate Program, Faculty of Education, Nakhon Si Thammarat Rajabhat University. Nakhon Si Thammarat, 80280, Thailand. \\ Tel./fax.: +66-75-392239, `email: jutamas_sup@nstru.ac.th
}

Manuscript received: 13 April 2020. Revision accepted: 22 May 2020

\begin{abstract}
Supmee V, Sangthong P, Songrak A, Suppapan J. 2020. Population genetic structure of Asiatic Hard Clam (Meretrix meretrix) in Thailand based on Cytochrome Oxidase subunit I gene sequence. Biodiversitas 21: 2702-2709. The Asiatic hard clam (Meretrix meretrix) is an important commercial clam in Thailand. Last decade, this species had a dramatic decrease. Thus, to conserve this species, genetic information is essential. In our study, 135 samples of M. meretrix were collected from 7 sampling sites along the Thailand coast. The genetic structure was examined based on the variation of the nucleotide sequence in cytochrome oxidase subunit I gene. Twenty haplotypes were identified. Numerous rare haplotypes were revealed indicating the existence of a large female effective population size. In the northern Gulf of Thailand population, the genetic diversity was low. The neutrality test and minimum spanning network showed experienced expansion events of M. meretrix in Thailand. The genetic structure showed that the M. meretrix population was separated into the Gulf of Thailand and the Andaman population. This finding was possibly caused by a disruption of gene flow from the ThaiMalay Peninsula and larval behavior. Our finding suggested that the construction management program to maintain the genetic diversity of this species could be separated into 2 conservation units.
\end{abstract}

Keywords: Mitochondrial DNA, genetic diversity, cytochrome oxidase subunit I, Asiatic hard clam, Thailand

\section{INTRODUCTION}

The Asiatic hard clam (Meretrix meretrix) is bivalve and widely distributed in the Indo-West Pacific. It is found in open coasts with more sand and less muddy bottom (Sienes et al. 2018). It is an economic bivalve in both the Gulf of Thailand and the Andaman Sea coast of Thailand (Fishery Statistics Analysis and Research Group 2017). Nowadays, the amount of $M$. meretrix in Thailand is decreasing because it is easy to catch in nature and fishermen fished it in various sizes without considering its sustainability. Further, the demand for $M$. meretrix consumption in Thailand is increasing, tends to overexploitation, and affects natural resource sustainability (Fishery Statistics Analysis and Research Group 2017).

The population genetic structure describes the genetic diversity pattern in the subpopulation. Usually, the marine species in subpopulation will breed within the group, and there may be some crossbreeding among subpopulations. Mating across populations creates opportunities for gene flow between sub-populations. If there is a large gene flow, the population will be slightly different and a low gene flow the population will be more different. In the marine species, the genetic structure is shaped by many factors, including geographical barriers, gene flow, population size, life history, and bottlenecks effect (Gilleard and Redman 2016).
Typically, mitochondrial DNA is exclusively inherited through the maternal line, high copy number, and lack of recombination ( $\mathrm{Li}$ et al. 2016). In our study, the information of the mitochondrial DNA sequencing on cytochrome oxidase subunit I gene (mtDNA COI) was used to discuss the population genetic structure of the $M$. meretrix in Thailand. The nucleotide sequencing of mtDNA $C O I$ has been used for studies population genetic structure of various clams such as Tridacna crocea and $T$. squamosa (Neo and Todd 2012), Atrina pectinata (Xue et al. 2014), and M. petechialis (Zheng et al. 2019). Several population genetic structure studies on $M$. meretrix have been revealed in Vietnam (Trang et al. 2018) and China ( $\mathrm{Gu}$ et al. 2015) but no studies have been reported from Thailand. The genetic information of the genetic structure in marine species is essential to the management of marine resources, especially when sharing information with biological studies, such as reproduction, behavior, and spawning time. Thus, the genetic information of $M$. meretrix in our study may be used for consideration in maintaining the genetic diversity of the natural stock to achieve the sustainable exploitation of $M$. meretrix in Thailand. 


\section{MATERIALS AND METHODS}

\section{Sampling sites and DNA extraction}

A total of 135 Asiatic hard clams (M. meretrix) were caught from 7 sampling sites along the Thailand coast including Chonburi (CB), Samut Songkhram (SM), Chumphon (CP), Surat Thani (SR), Nakhon Si Thammarat (NS), Songkhla (SK), Satun (ST), and Trang (TG) (Table 1, Figure 1). Fresh samples were preserved on the ice and transported to a laboratory for DNA extraction. Total genomic DNA was isolated from the adductor muscle tissue followed by the manufacturer protocol from the Genomic DNA Extraction Kit (Tiangen BioTech, China).

\section{PCR amplification and nucleotide sequencing}

A region of the mtDNA $C O I$ gene was amplified by Polymerase chain reaction (PCR). Primer COI MM F: 5' GCA GTA TTA AAA TTT CGA TCT 3' and COI_ MM_ F: 5' GTG GTT TTG GAA ATT GGT TG 3' were designed for amplifying target DNA. Polymerase chain reaction was conducted in total volume $50 \mu \mathrm{l}$ consisting 10X Taq buffer $5 \mu \mathrm{l}, 25 \mathrm{mM} \mathrm{\textrm {MCl } _ { 2 }} 5 \mu \mathrm{l}, 2 \mathrm{mM}$ dNTPs mix $4 \mu \mathrm{l}, 10 \mu \mathrm{M}$ forward and reverse primers $2 \mu \mathrm{l}$ each, 2.5 unit Taq DNA polymerase (Thermo SCIENTIFIC, USA) $0.5 \mu \mathrm{l}$, DNA template $5 \mu \mathrm{l}(50-100 \mathrm{ng})$ and ultrapure water $26.5 \mu$ l. The polymerase chain reaction was performed in a thermocycler (Major Cycler, CYCLER, TAIWAN). The PCR conditions was followed; step 1-first denaturation at $94{ }^{\circ} \mathrm{C}$ for $4 \mathrm{~min}$; step $2-35$ cycles of $94^{\circ} \mathrm{C}$ for $40 \mathrm{sec}, 51^{\circ} \mathrm{C}$ for $1 \mathrm{~min}, 72{ }^{\circ} \mathrm{C}$ for $1 \mathrm{~min}$; step 3 -final extension at $72{ }^{\circ} \mathrm{C}$ for $10 \mathrm{~min}$. The PCR products were purified using Gel/PCR Purification Mini Kit (TiangenBioTech, China) and sent to $1^{\text {ST }}$ Base Laboratory, Malaysia for direct sequencing.

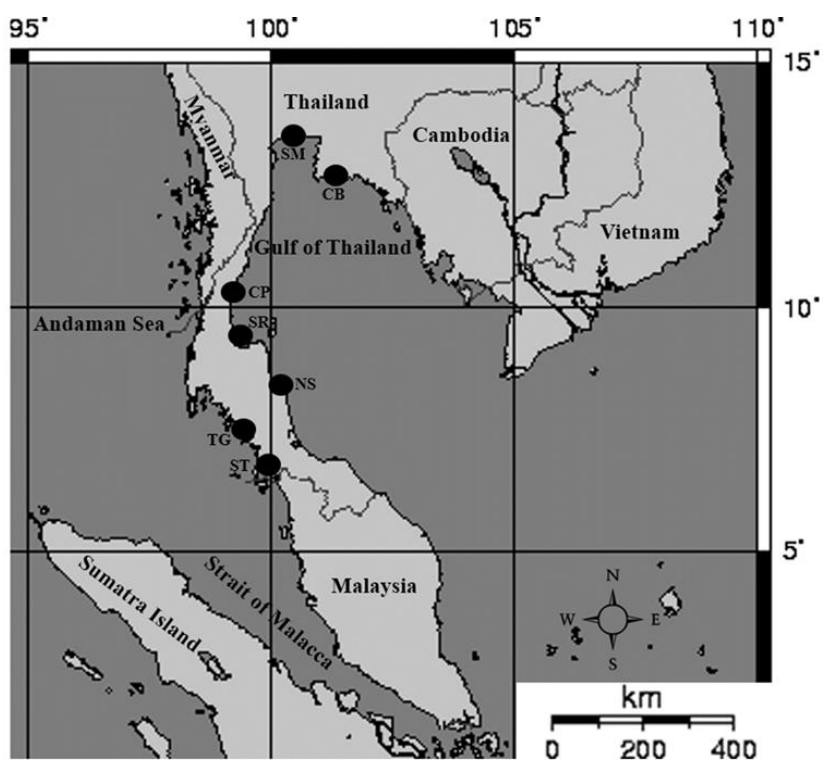

Figure 1. Sampling areas of the M. meretrix from the Thailand coast: the northern Gulf of Thailand; Chonburi (CB), Samut Songkhram (SM): the southern Gulf of Thailand; Chumphon (CP), Surat Thani (SR), Nakhon Si Thammarat (NS): the Andaman Sea; Satun (ST), Trang (TG)

\section{Data analysis}

Genetic diversity

Sequences were viewed and confirmed with the BLAST program in GenBank. All sequences were edited to $446 \mathrm{bp}$ and aligned using ClustalW version 2.0.10 (Larkin et al. 2007). The polymorphic sites, nucleotide diversity $(\pi)$ (Nei and Tajima 1981), and haplotype diversity $(h)$ (Nei 1987) were calculated using DnaSP version 6.00 (Rozas et al. 2017). The neutrality test was estimated using Tajima's $D$ test (Tajima 1989) and Fu's Fs test (Fu 1997) as implement in ARLEQUIN v. 3.5 (Excoffier and Lischer 2010) with 10,000 permutations $(p<0.05)$.

\section{Population genetic structure}

The population genetic structure of $M$. meretrix was examined under six assumptions according to the geographic-based structures. Firstly, samples were separated into seven populations regarding the sampling sites (CB, SM, CP, SR, NS, ST, and TG). Secondly, samples were determined according to the geographic region: the Gulf of Thailand (CB, SM, CP, SR, and NS) and the Andaman Sea (ST, and TG). Thirdly, samples were divided according to the three geographic regions: the northern Gulf of Thailand (CB and SM), the southern Gulf of Thailand (CP, SR, and NS) and the Andaman Sea (ST and TG). Fourthly, samples were determined according to the two geographic regions: the northern Gulf of Thailand (CB and SM) and the Andaman Sea (ST and TG). Fifthly, samples were separated according to the two geographic regions: the southern Gulf of Thailand (CP, SR, and NS) and the Andaman Sea (ST and TG). Sixthly, samples were divided according to the two geographic regions: the southern Gulf of Thailand (CP, SR, and NS) and the northern Gulf of Thailand (CB and SM).

An analysis of molecular variance (AMOVA) was used to examine the genetic differentiation within and among putative populations using ARLEQUIN v. 3.5 (Excoffier and Lischer 2010). The $\Phi$-statistic analogs were estimated the different levels $\left(\Phi_{C T}\right.$; among groups, $\Phi_{S C}$; among populations within groups and $\Phi_{S T}$; within populations) and tested by 10,000 permutations $(\mathrm{p}<0.05)$. Pairwise $F_{S T}$ were estimated genetic distances between all combinations of populations. The significance of the pairwise was determined with 10,000 permutations $(p<0.05)$. The neighbor-joining (NJ) phylogenetic tree the under Kimura 2-parameter model was constructed using MEGA 7.0 (Kumar et al. 2016) to depict the relationships among haplotypes. The statistical of the tree topology robustness was obtained by bootstrapping using 1,000 replicates. A minimum spanning network based on the mean number of pairwise differences among haplotypes of the mtDNA COI was constructed using ARLEQUIN v. 3.5 (Excoffier and Lischer, 2010) and drawn by hand.

\section{RESULTS AND DISCUSSION}

\section{Genetic diversity}

The length of the mtDNA COI fragment was 446 base pairs and 20 haplotypes were determined. Twenty-one 
polymorphic sites were observed, including 13 singleton variable sites and 8 parsimony informative sites. The average nucleotide composition of $\mathrm{A}, \mathrm{T}, \mathrm{G}$, and $\mathrm{C}$ were $43.7 \%, 20.4 \%, 14.3 \%$, and $21.6 \%$, respectively. The A/T base content was $64.1 \%$ and $\mathrm{G} / \mathrm{C}$ was $35.9 \%$. The variable sites among 20 mtDNA COI haplotypes were shown in Table 1.

Haplotype diversity was ranged from $0.195 \pm 0.115$ at SM to $0.693 \pm 0.114$ at SR. Haplotype diversity $(h)$ of the northern Gulf of Thailand, the southern Gulf of Thailand, the Andaman Sea and the total of Thailand was
$0.249 \pm 0.093,0.587 \pm 0.075,0.549 \pm 0.066$ and $0.507 \pm 0.052$, respectively (Table 2). Meanwhile, the nucleotide diversity $(\pi)$ of the northern Gulf of Thailand, the southern Gulf of Thailand, the Andaman Sea and the total of Thailand was $0.00059 \pm 0.00023,0.00318 \pm 0.00072,0.00149 \pm 0.00028$ and $0.00210 \pm 0.00038$, respectively. The range of nucleotide diversity was $0.00045 \pm 0.00027$ at $\mathrm{SM}$ to $0.00551 \pm 0.00132$ at CP (Table 2). The number of samples, number of polymorphic sites, number of haplotypes, haplotype diversity, and nucleotide diversity within either population were shown in Table 2.

Table 1. Variation nucleotide position among 20 mtDNA COI haplotypes of the M. meretrix from the 7 sampling sites along the Thailand coast. All haplotypes are compared with haplotype MM 01. The dot indicates identical nucleotides

\begin{tabular}{|c|c|c|c|c|c|c|c|c|c|c|c|c|c|c|c|c|c|c|c|c|c|}
\hline \multirow{4}{*}{ Haplotype } & \multicolumn{21}{|c|}{ Nucleotide positions } \\
\hline & 1 & 2 & 3 & 1 & 1 & 1 & 1 & 1 & 1 & 1 & 1 & 2 & 2 & 2 & 2 & 2 & 3 & 3 & 3 & 3 & 4 \\
\hline & 1 & 7 & 1 & 3 & 3 & 4 & 4 & 6 & 6 & 8 & 9 & 1 & 3 & 5 & 7 & 7 & 2 & 4 & 4 & 4 & $\mathbf{0}$ \\
\hline & & & & 3 & 7 & 2 & 5 & 8 & 9 & 8 & 3 & 6 & 2 & 8 & 2 & 3 & 6 & 0 & 6 & 7 & 7 \\
\hline MM 01 & $\mathrm{~T}$ & A & $\mathrm{C}$ & $\mathrm{G}$ & A & A & G & $\mathrm{T}$ & $\mathrm{G}$ & $\mathrm{G}$ & $\mathrm{C}$ & $\mathrm{A}$ & $\mathrm{A}$ & $\mathrm{C}$ & $\mathrm{G}$ & $\mathrm{G}$ & G & A & G & $\mathrm{T}$ & G \\
\hline MM 02 & $\mathrm{C}$ & G & $\mathrm{T}$ & A & . & G & . & $\mathrm{C}$ & A & . & . & . & $\mathrm{T}$ & $\mathrm{T}$ & A & A & A & G & A & $\mathrm{C}$ & . \\
\hline MM 03 & . & . & . & . & . & G & . & . & . & . & . & . & . & . & . & . & . & . & . & . & . \\
\hline MM 04 & & . & . & A & . & G & . & . & . & . & . & . & $\mathrm{T}$ & & . & . & . & G & . & $\mathrm{C}$ & . \\
\hline MM 05 & $\mathrm{C}$ & & $\mathrm{T}$ & . & . & - & . & $\mathrm{C}$ & A & . & . & $\mathrm{C}$ & . & $\mathrm{T}$ & A & A & A & G & A & $\mathrm{C}$ & . \\
\hline MM 06 & $\mathrm{C}$ & G & A & A & . & G & . & $\mathrm{C}$ & A & . & . & . & $\mathrm{T}$ & $\mathrm{T}$ & A & A & A & G & A & & . \\
\hline MM 07 & $\mathrm{C}$ & G & $\mathrm{T}$ & A & . & G & . & $\mathrm{C}$ & A & . & . & . & $\mathrm{T}$ & $\mathrm{T}$ & A & A & A & G & A & $\mathrm{C}$ & . \\
\hline MM 08 & $\mathrm{C}$ & G & $\mathrm{T}$ & A & . & G & . & $\mathrm{C}$ & A & . & . & . & $\mathrm{C}$ & $\mathrm{T}$ & A & A & A & G & A & $\mathrm{C}$ & . \\
\hline MM 09 & $\mathrm{C}$ & G & $\mathrm{T}$ & A & . & G & A & $\mathrm{C}$ & A & . & . & $\mathrm{C}$ & $\mathrm{T}$ & $\mathrm{T}$ & A & A & A & G & A & $\mathrm{C}$ & . \\
\hline MM 10 & $\mathrm{C}$ & G & $\mathrm{T}$ & A & . & G & . & $\mathrm{C}$ & . & . & . & . & $\mathrm{T}$ & $\mathrm{T}$ & A & A & A & G & A & $\mathrm{C}$ & . \\
\hline MM 11 & $\mathrm{C}$ & G & $\mathrm{T}$ & A & . & G & . & $\mathrm{C}$ & A & . & . & . & $\mathrm{T}$ & . & A & A & A & G & A & $\mathrm{C}$ & . \\
\hline MM 12 & $\mathrm{C}$ & G & $\mathrm{T}$ & A & . & G & . & . & A & . & . & . & $\mathrm{T}$ & $\mathrm{T}$ & A & A & A & G & A & $\mathrm{C}$ & . \\
\hline MM 13 & $\mathrm{C}$ & G & $\mathrm{T}$ & A & $\mathrm{G}$ & . & 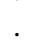 & $\mathrm{C}$ & A & . & & . & $\mathrm{T}$ & $\mathrm{T}$ & A & A & A & G & A & $\mathrm{C}$ & . \\
\hline MM 14 & $\mathrm{C}$ & $\mathrm{G}$ & $\mathrm{T}$ & . & . & & A & $\mathrm{C}$ & A & & $\mathrm{T}$ & C & $\mathrm{T}$ & $\mathrm{T}$ & A & A & A & G & A & $\mathrm{C}$ & . \\
\hline MM 15 & $\mathrm{C}$ & $\mathrm{G}$ & $\mathrm{T}$ & A & . & G & . & $\mathrm{C}$ & A & $\mathrm{C}$ & . & . & $\mathrm{T}$ & $\mathrm{T}$ & A & A & A & G & A & $\mathrm{C}$ & . \\
\hline MM 16 & $\mathrm{C}$ & G & $\mathrm{T}$ & A & . & G & . & $\mathrm{C}$ & A & . & . & . & $\mathrm{T}$ & $\mathrm{T}$ & A & A & A & G & A & . & . \\
\hline MM 17 & $\mathrm{C}$ & G & $\mathrm{T}$ & A & . & G & . & $\mathrm{C}$ & A & . & . & . & $\mathrm{T}$ & $\mathrm{T}$ & A & A & A & G & A & $\mathrm{C}$ & A \\
\hline MM 18 & $\mathrm{C}$ & G & $\mathrm{T}$ & A & . & G & . & $\mathrm{C}$ & A & . & . & . & $\mathrm{T}$ & $\mathrm{T}$ & A & A & A & G & A & $\mathrm{C}$ & . \\
\hline MM 19 & $\mathrm{C}$ & G & $\mathrm{T}$ & A & . & G & & $\mathrm{C}$ & A & . & . & . & $\mathrm{T}$ & $\mathrm{T}$ & A & A & $\mathrm{T}$ & G & A & $\mathrm{C}$ & . \\
\hline MM 20 & $\mathrm{C}$ & G & $\mathrm{T}$ & A & . & G & . & $\mathrm{C}$ & A & . & . & $\mathrm{G}$ & $\mathrm{T}$ & $\mathrm{T}$ & A & A & A & $\mathrm{G}$ & A & $\mathrm{C}$ & \\
\hline
\end{tabular}

Table 2. Collecting localities, number of individuals per sampling site $(N)$, number of polymorphic sites, haplotype diversity $(h)$, nucleotide diversity $(\pi)$ and neutrality test parameter of M. meretrix along the Thailand coast

\begin{tabular}{lccccccc}
\hline Collecting localities & $\boldsymbol{N}$ & $\begin{array}{c}\text { No. } \\
\text { polymorphic } \\
\text { sites }\end{array}$ & $\begin{array}{c}\text { No. } \\
\text { haplotypes }\end{array}$ & $\begin{array}{c}\text { Haplotype } \\
\text { diversity }(\boldsymbol{h}) \\
(\mathbf{m e a n} \pm \text { SD) }\end{array}$ & $\begin{array}{c}\text { Nucleotide diversity } \\
(\boldsymbol{\pi}) \\
(\mathbf{m e a n} \pm \mathbf{S D})\end{array}$ & Tajima's $\boldsymbol{D}$ & Fu' Fs \\
\hline Chonburi (CB) & 18 & 3 & 4 & $0.314 \pm 0.138$ & $0.00075 \pm 0.00035$ & -1.71304 & -2.60267 \\
Samut Sakhon (SM) & 20 & 2 & 3 & $0.195 \pm 0.115$ & $0.00045 \pm 0.00027$ & -1.51284 & -1.86305 \\
Chumphon (CP) & 19 & 9 & 4 & $0.684 \pm 0.092$ & $0.00551 \pm 0.00132$ & $0.24989^{*}$ & $1.18703^{*}$ \\
SuratThani (SR) & 18 & 7 & 6 & $0.693 \pm 0.114$ & $0.00259 \pm 0.00064$ & $-1.46445^{*}$ & $-3.25454^{*}$ \\
Nakhon Si Thammarat (NS) & 21 & 5 & 5 & $0.352 \pm 0.131$ & $0.00107 \pm 0.00047$ & $-1.98137^{*}$ & $-3.06773^{*}$ \\
Satun (ST) & 20 & 4 & 4 & $0.595 \pm 0.098$ & $0.00176 \pm 0.00046$ & -0.088138 & -0.56034 \\
Trang (TG) & 19 & 3 & 4 & $0.526 \pm 0.089$ & $0.00126 \pm 0.00026$ & -0.04521 & -0.03167 \\
Northern Gulf of Thailand & 38 & 5 & 6 & $0.249 \pm 0.093$ & $0.00059 \pm 0.00023$ & -0.98642 & -2.14589 \\
Southern Gulf of Thailand & 58 & 15 & 14 & $0.587 \pm 0.075$ & $0.00318 \pm 0.00072$ & $-1.57892^{*}$ & $-1.94538^{*}$ \\
Andaman Sea & 39 & 4 & 4 & $0.549 \pm 0.066$ & $0.00149 \pm 0.00028$ & -0.56984 & -4.23568 \\
Total & 135 & 21 & 20 & $0.507 \pm 0.052$ & $0.00210 \pm 0.00038$ & $-1.04977^{*}$ & $-1.45614^{*}$ \\
\hline
\end{tabular}

Note: *significant differentiation $(p<0.05)$ 
Twenty haplotypes were identified. In total, 7 haplotypes were shared; 2 haplotypes were shared within the population (MM 09 and MM 14) and 5 haplotypes were shared among the population (MM 01, MM 02, MM 03, MM 04, and MM 16). Haplotype MM 02 was shared by all populations, while haplotype MM 01, MM 03, and MM 04 were shared only in the Andaman Sea populations. The remaining 13 haplotypes were rare haplotype (MM 05, MM 06, MM 07, MM 08, MM 10, MM 11, MM 12, MM 13, MM 15, MM 17, MM 18, MM 19, MM 20) (Table 3). SR and NS population possessed 4 rare haplotypes, $\mathrm{CB}$ and SM population had 2 rare haplotypes, and the $\mathrm{CP}$ population possessed 1 rare haplotype (Table 3). Tajima's $D$ statistic of the total population and withinpopulation in the southern Gulf of Thailand was-1.04977 and-1.57892, and statistically significant. Meanwhile, the population of the northern Gulf of Thailand and the Andaman Sea, the $D$ statistic was-0.98642 and-0.56984, and non-statistically significant (Table 2). Tajima's $D$ statistic of CP, SR, and NS populations, were statistically significantly negative, while this statistic for the CB, SM, ST, and TG populations was statistically non-significantly negative (Table 2). Fu's Fs statistics of the total population and within-population in the southern Gulf of Thailand was statistically significant (-1.45614 and-1.94538). In the meantime, the $F s$ statistic of the population in the northern Gulf of Thailand and the Andaman Sea was-2.14589 and4.23568, and non-statistically significant (Table 1). Fu's Fs statistic was statistically significantly negative in CP, SR, and NS populations, and this statistic was statistically nonsignificantly negative for the CB, SM, ST, and TG populations (Table 2).

\section{Population genetic structure}

The AMOVA analysis revealed the genetic structure in 5 putative genetic structure. Firstly, the M. meretrix population along the Thailand coast showed a different statistically significant $\left(\Phi_{S T}=0.109, p=0.000\right)$. Secondly, the Gulf of Thailand population was significantly different from the Andaman Sea $\left(\Phi_{C T}=0.058, p=0.036\right)$. Thirdly, the northern Gulf of Thailand, the southern Gulf of Thailand and the Andaman sea showed a different statistically significant $\left(\Phi_{C T}=0.059, p=0.041\right)$. Fourthly, the northern Gulf of Thailand showed significant differences with the Andaman Sea $\left(\Phi_{C T}=0.153, p=0.038\right)$. Fifthly, the southern Gulf of Thailand revealed significant differences from the Andaman Sea $\left(\Phi_{C T}=0.065, p=0.045\right)$. Meanwhile, the $\Phi$ statistic of the putative structure showed no different significant between the northern and southern Gulf of Thailand $\left(\Phi_{C T}=0.020, p=0.200\right)$ (Table 4). The pairwise $F_{S T}$ showed significant differences among the population between the Gulf of Thailand population and the Andaman Sea population. Every pairwise $F_{S T}$ among sampling populations was shown in Table 5. The neighbor-joining phylogenetic tree showed that the haplotype MM 01, MM 03, and MM 04 was divided into the Andaman Sea population and another haplotype was grouped into the Gulf of Thailand population (Figure 2). The topology of the minimum spanning network showed a star-like network. Haplotype MM 02 was a common haplotype and connected directly with other haplotypes by 1-5 mutation steps. The minimum spanning network was divided into two groups from a distinct pattern of geographic structure among 20 haplotypes. The Gulf of Thailand group consisted of haplotype MM 02, MM 05, MM 06, MM 07, MM 08 MM 09, MM 10, MM 11, MM 12, MM 13, MM 14, MM 15, MM 16, MM 17, MM 18, MM 19, and MM 20. The Andaman Sea group consisted of haplotype MM 01, MM 03, and MM 04. The haplotype of the Gulf of Thailand group and the Andaman Sea group was separated by 5 mutation steps. (Figure 3).

\section{Discussion \\ Genetic diversity}

The genetic information of $20 \mathrm{mtDNA}$ COI haplotypes of $M$. meretrix in Thailand using the nucleotide sequence of mtDNA COI was analyzed. In our study, the A/T base content was higher than $\mathrm{G} / \mathrm{C}$ base content, concordant with other reports that mtDNA COI sequence of Meretrix species is an $\mathrm{A} / \mathrm{T}$ rich sequence such as $M$. meretrix (Wang et al. 2016), and M. petechialis (Zheng et al. 2019). The $\mathrm{A} / \mathrm{T}$ rich base composition is a common feature of the mitochondrial genome in animals (Fourdrilis et al. 2018).

Many rare haplotypes were presented indicated that the large female effective population size of the $M$. meretrix was existence (Croos and Pálsson 2010). Numerous rare haplotypes are the retention of a new mutation and reflect a largely female population size. High haplotype diversity and low nucleotide diversity were presented in all sampling populations and all geographic regions. This pattern is generated by new mutations accumulation in a sudden population expansion (Chu et al. 2012). This genetic diversity pattern was reported in various clam species including Donax vittatus (Fernández-Pérez et al. 2017), $M$. petechialis (Wang et al. 2017a), and M. meretrix (Trang et al. 2018).

Table 3. Haplotype distributions of $M$. meretrix from 7 localities along the Thailand coast. Stations codes are given in Table 2

\begin{tabular}{lcccccccc}
\hline Haplotype & CB & SM & CP & SR & NS & ST & TG & Total \\
\hline MM 01 & - & - & - & - & - & 9 & 3 & 12 \\
MM 02 & 15 & 18 & 13 & 12 & 17 & 3 & 4 & 82 \\
MM 03 & - & - & - & - & - & 1 & 6 & 7 \\
MM 04 & - & - & - & - & - & 7 & 6 & 13 \\
MM 05 & - & - & - & - & 1 & - & - & 1 \\
MM 06 & - & - & - & - & 1 & - & - & 1 \\
MM 07 & - & - & - & - & 1 & - & - & 1 \\
MM 08 & - & - & - & - & 1 & - & - & 1 \\
MM 09 & - & - & - & 2 & - & - & - & 2 \\
MM 10 & - & - & - & 1 & - & - & - & 1 \\
MM 11 & - & - & - & 1 & - & - & - & 1 \\
MM 12 & - & - & - & 1 & - & - & - & 1 \\
MM 13 & - & - & - & 1 & - & - & - & 1 \\
MM 14 & - & - & 4 & - & - & - & - & 4 \\
MM 15 & - & - & 1 & - & - & - & - & 1 \\
MM 16 & 1 & - & 1 & - & - & - & - & 2 \\
MM 17 & - & 1 & - & - & - & - & - & 1 \\
MM 18 & - & 1 & - & - & - & - & - & 1 \\
MM 19 & 1 & - & - & - & - & - & - & 1 \\
MM 20 & 1 & - & - & - & - & - & - & 1 \\
Total & 18 & 20 & 19 & 18 & 21 & 20 & 19 & 135 \\
\hline
\end{tabular}


Table 4. An analysis of molecular variance (AMOVA) of M. meretrix in Thailand

\begin{tabular}{|c|c|c|c|c|c|}
\hline Source of variation & df & $\begin{array}{l}\text { Sum of } \\
\text { squares }\end{array}$ & $\begin{array}{l}\text { Variance } \\
\text { components }\end{array}$ & $\begin{array}{l}\text { Percentage } \\
\text { of variation }\end{array}$ & $p$-value \\
\hline \multicolumn{6}{|l|}{ Single region } \\
\hline Among populations & 6 & 8.545 & $0.050 \mathrm{Va}$ & 10.99 & \multirow[t]{3}{*}{$\Phi_{S T}=0.109 *(p=0.000)$} \\
\hline Within populations & 128 & 53.936 & $0.421 \mathrm{Vb}$ & 89.01 & \\
\hline Total & 134 & 62.481 & 0.473 & & \\
\hline \multicolumn{6}{|l|}{ Gulf of Thailand and Andaman Sea } \\
\hline Among groups & 1 & 2.752 & $0.028 \mathrm{Va}$ & 5.85 & $\Phi_{C T}=0.058 *(p=0.036)$ \\
\hline Among populations within groups & 5 & 5.794 & $0.038 \mathrm{Vb}$ & 7.85 & $\Phi_{S C}=0.083 *(p=0.001)$ \\
\hline Within populations & 128 & 53.936 & $0.421 \mathrm{Vc}$ & 86.30 & $\Phi_{S T}=0.137 *(p=0.000)$ \\
\hline Total & 134 & 62.481 & 0.488 & & \\
\hline \multicolumn{6}{|c|}{ Northern Gulf of Thailand, southern Gulf of Thailand, and Andaman Sea } \\
\hline Among groups & 2 & 4.532 & $0.028 \mathrm{Va}$ & 5.96 & $\Phi_{C T}=0.059 *(p=0.041)$ \\
\hline Among populations within groups & 4 & 4.013 & $0.030 \mathrm{Vb}$ & 6.29 & $\Phi_{S C}=0.066 *(p=0.020)$ \\
\hline Within populations & 128 & 53.936 & $0.421 \mathrm{Vc}$ & 87.75 & $\Phi_{S T}=0.122 *(p=0.000)$ \\
\hline Total & 134 & 62.481 & 0.480 & & \\
\hline \multicolumn{6}{|c|}{ Northern Gulf of Thailand and Andaman Sea } \\
\hline Among groups & 1 & 1.737 & $0.041 \mathrm{Va}$ & 15.40 & $\Phi_{C T}=0.153 *(p=0.038)$ \\
\hline Among populations within groups & 2 & 0.248 & $-0.005 \mathrm{Vb}$ & -2.14 & $\Phi_{S C}=-0.025(p=0.723)$ \\
\hline Within populations & 73 & 17.236 & $0.236 \mathrm{Vc}$ & 86.75 & $\Phi_{S T}=0.132^{*}(p=0.003)$ \\
\hline Total & 76 & 19.221 & 0.272 & & \\
\hline \multicolumn{6}{|c|}{ Southern Gulf of Thailand and Andaman Sea } \\
\hline Among groups & 1 & 3.167 & $0.040 \mathrm{Va}$ & 6.53 & $\Phi_{C T}=0.065 *(p=0.045)$ \\
\hline Among populations within groups & 3 & 3.878 & $0.039 \mathrm{Vb}$ & 6.38 & $\Phi_{S C}=0.068 *(p=0.021)$ \\
\hline Within populations & 92 & 49.203 & $0.534 \mathrm{Vc}$ & 87.10 & $\Phi_{S T}=0.129 *(p=0.000)$ \\
\hline Total & 96 & 56.247 & 0.614 & & \\
\hline \multicolumn{6}{|c|}{ Northern and southern of Gulf of Thailand } \\
\hline Among groups & 1 & 1.781 & $0.010 \mathrm{Va}$ & 2.05 & $\Phi_{C T}=0.020(p=0.200)$ \\
\hline Among populations within groups & 3 & 3.900 & $0.044 \mathrm{Vb}$ & 8.64 & $\Phi_{S C}=0.088 *(p=0.015)$ \\
\hline Within populations & 91 & 41.434 & $0.455 \mathrm{Vc}$ & 89.31 & $\Phi_{S T}=0.106 *(p=0.001)$ \\
\hline Total & 95 & 47.115 & 0.509 & & \\
\hline
\end{tabular}

Note: *significant differentiation $(p<0.05)$

Table 5. Population pairwise $F_{S T}$ values of $M$. meretrix

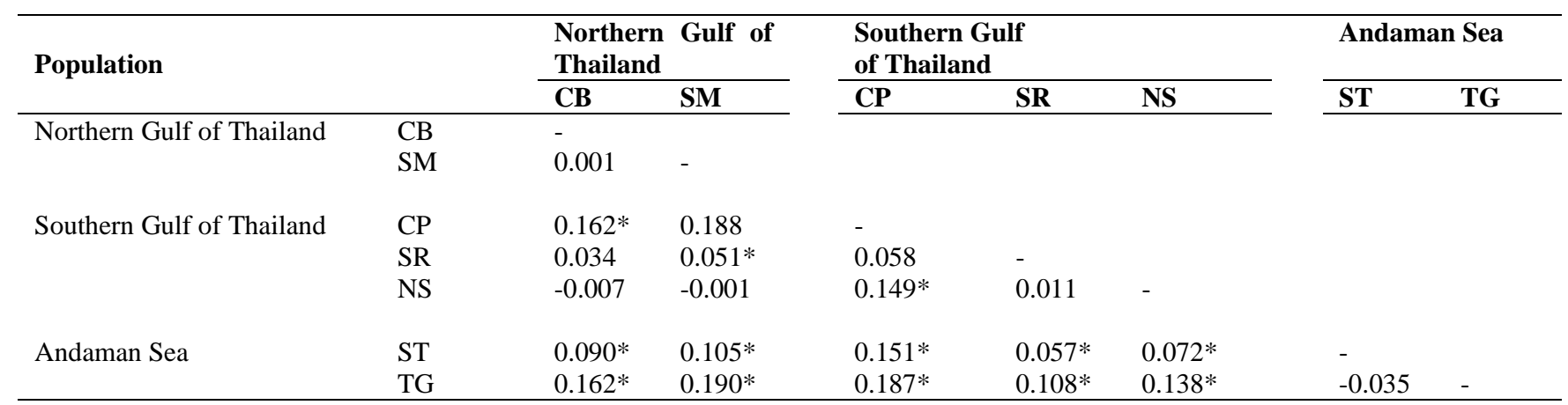

Note: *significant differentiation $(p<0.05)$

Generally, nucleotide diversity displays the mean number of differences among all pairs of haplotypes in each population and used to discuss a genetic diversity in the population (Ma et al. 2010). The larger nucleotide diversity value indicates a higher genetic diversity in the population (Wang et al. 2017b). Nucleotide diversity can be influenced by many factors including population size, life history, and environmental change (Ma et al. 2010). In this study, the lowest nucleotide diversity value was found in the northern Gulf of Thailand population indicating a low genetic diversity in this region. Last decade, the harvesting of $M$. meretrix in the northern Gulf of Thailand was changed to the machine harvesting, it fished $M$. meretrix in various sizes without considering its sustainability. As a result, the population size of $M$. meretrix in the northern Gulf of Thailand decreased dramatically. Therefore, the overexploitation of the $M$. meretrix in natural resources in the northern Gulf of Thailand population may result in genetic bottleneck.

In the Thailand population, the neutrality test revealed negative and deviated significantly from the neutral population. The statistically significant negative value in Tajima's $D$ test might have been caused by a population expansion (Omori and Wu 2017). Further, Fu's Fs 
statistics, a strong statistical test for detecting demographic expansion from mtDNA sequence data (Ramirez-Soriano et al. 2008) showed the statistically significant negative value, indicated a population expansion. Thus, these results suggested that the $M$. meretrix population in Thailand might have experienced expansion events. Further, Tajima's $D$ and Fu's $F s$ results in the southern Gulf of Thailand population was statistically significant negative value indicated a population expansion had undergone. For the northern Gulf of Thailand and the Andaman Sea population, Tajima's $D$ and Fu's $F s$ were negative but no significant deviation from the neutral state. These results support for slight population expansion and the nonsignificant negative value may be caused by the expansion that has been restricted to sampling sites (Rosly et al. 2013). Besides, a minimum spanning network showed a star-like topology indicated a signature of sudden population expansion (Slatkin and Hudson, 1991).

\section{Population genetic structure}

Population genetic structure in several marine animals caused by gene flow disruption. The geographic barrier, dispersive ability, and larva behavior are the main factor to prevent or promote gene flow among the population (Wang et al. 2013). In our study, the AMOVA, pairwise $F_{S T}$, the neighbor-joining phylogenetic tree, and minimum spanning network could be genetically separated $M$. meretrix population into the Gulf of Thailand population and the Andaman Sea population. The genetic differentiation of the $M$. meretrix population between these two seas may cause by two factors. Firstly, Thailand's coast is located between the Pacific Oceans (Gulf of Thailand) and the Indian Oceans (Andaman Sea), separated by the Thai-Malaysian peninsula. Thus, this geographic barrier may prevent the gene flow of $M$. meretrix living in the Gulf of Thailand and the Andaman Sea. Secondly, the first larva stage of many marine animals is a planktonic larva. It is a free-moving larva and migrates to the open sea by the current. So, the water circulation is to promote a dispersal ability of many marine animals and maintain gene flow between populations (Johannesson et al. 2018). The planktonic larva stage of $M$. meretrix was mostly complete and settlement on 12 days (Sienes et al. 2018; Hamli et al. 2019). As the short of planktonic larva stage and the rapid settlements of $M$. meretrix may reduce a dispersion ability. Thus, the larva behavior of $M$. meretrix may decrease gene flow for a long geographic distance between the Gulf of Thailand and the Andaman Sea population. The genetic structure between these two regions has been reported in various marine species, such as Hippocampus kuda (Panithanarak et al. 2010), Paphia undulata (Donrung et al. 2011), and Varuna litterata (Suppapan et al. 2017).

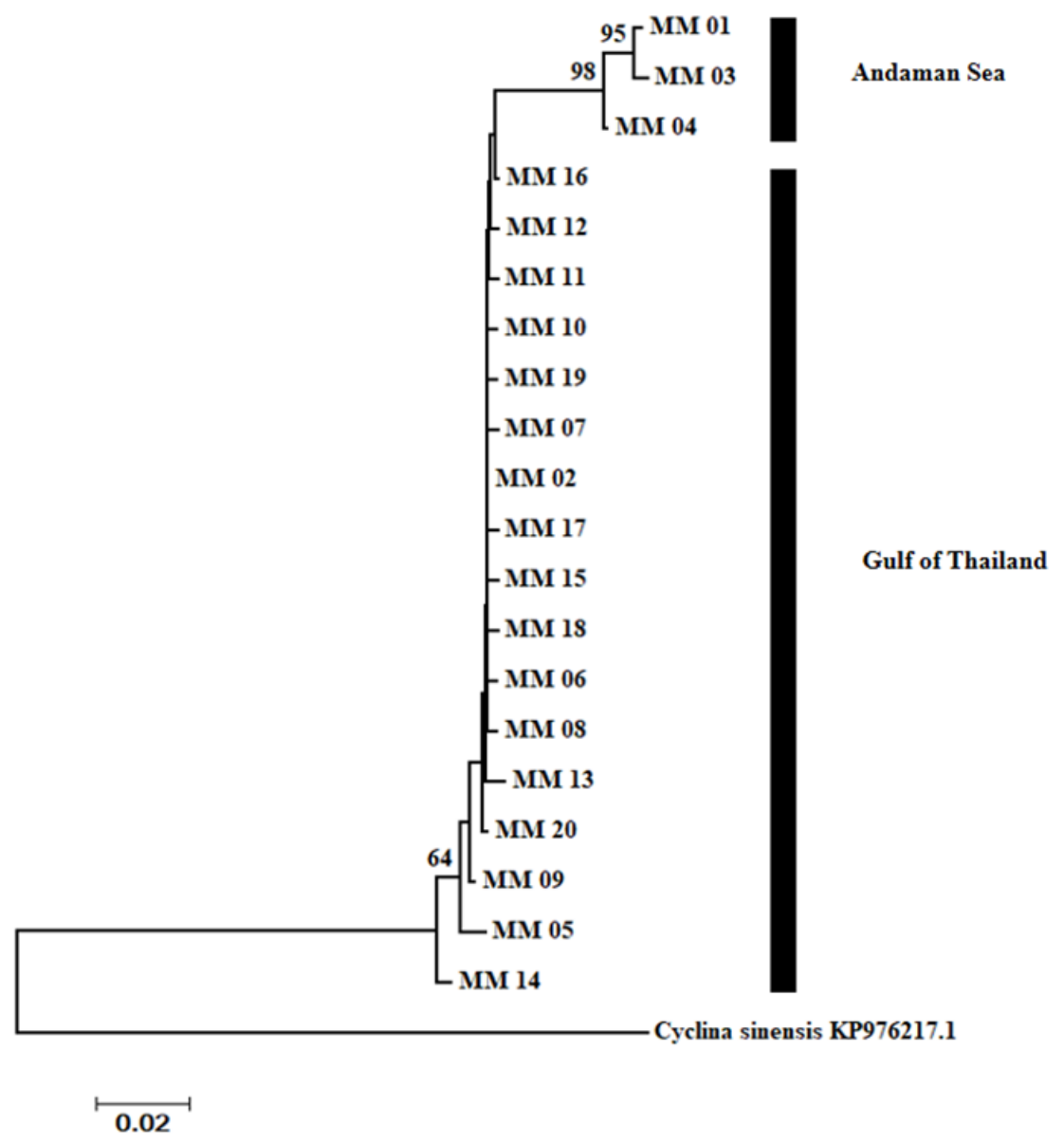

Figure 2. Neighbor-joining phylogenetic tree based on the Kimura 2-parameter model and Cyclina sinensis as the outgroup. The number on the branches is bootstrap values. 


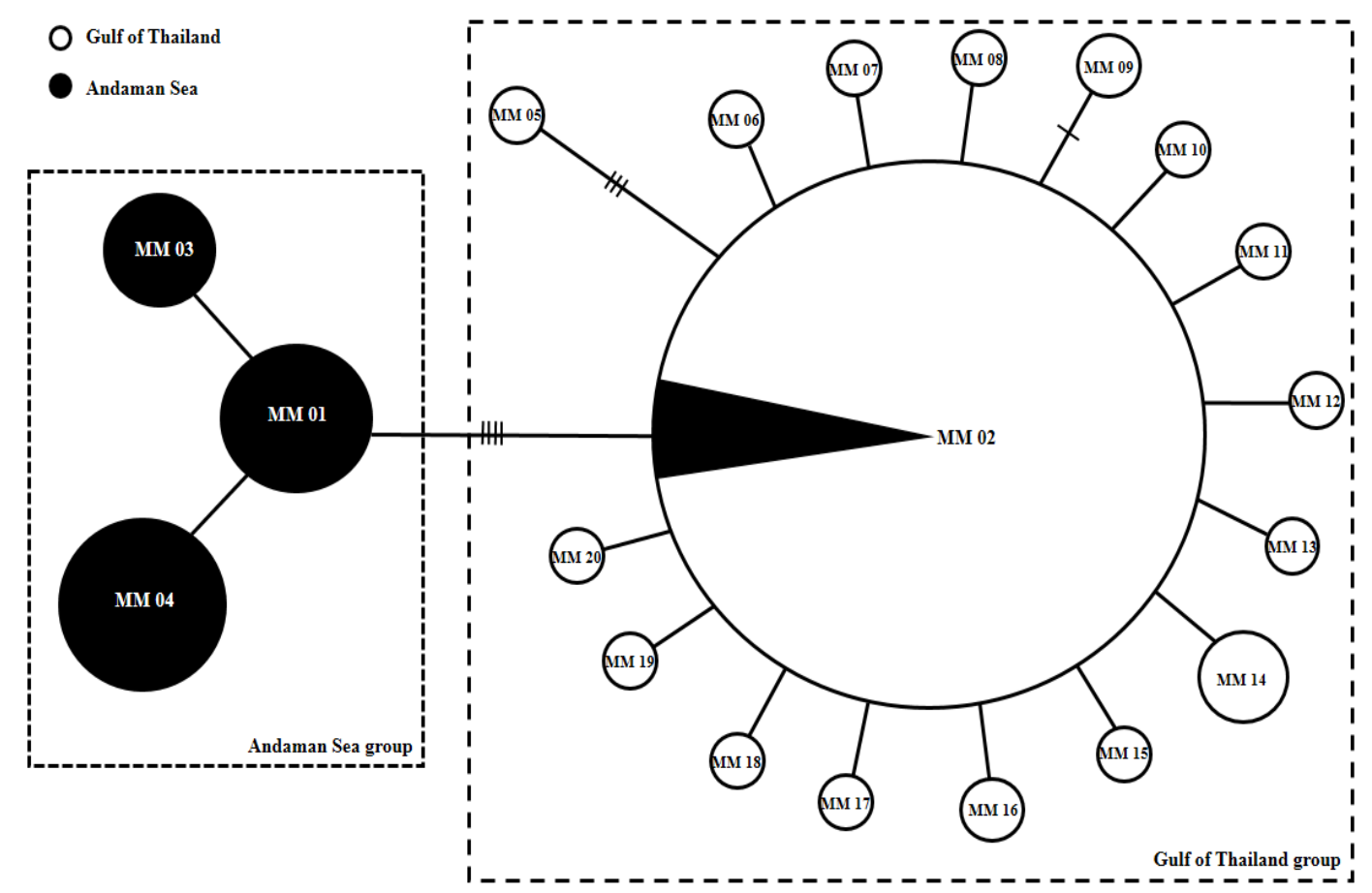

Figure 3. Minimum spanning network based on $20 \mathrm{mtDNA}$ COI haplotypes of the $M$. meretrix. Circles are haplotypes and the proportion size is the observed frequency. The white and black color of the circle indicates the geographic region. The single line connecting directly between haplotype indicating a haplotype separating by one mutation step. The number of vertical bars on the connecting line is an increasing number of mutation steps.

Our finding showed that M. meretrix living along the Gulf of Thailand was only 1 population. Genetic homogeneity of the M. meretrix population in the Gulf of Thailand was plausibly maintained by two factors. Firstly, a lack of geographic barriers and a short geographic distance in the Gulf of Thailand maybe not prevented the gene flow of the $M$. meretrix population between the northern and the southern Gulf of Thailand. Secondly, the sea current in the Gulf of Thailand is a clockwise direction during the southwestern monsoon and a counter-clockwise direction in the northeastern monsoon (Saramul 2017). Further, the reproductive cycle of $M$. meretrix is biannual (Hamli et al. 2019) concordant with the monsoon period. Therefore, the homogenizing of the planktonic larva by sea circulation in the reproductive time may be maintained the gene flow of the M. meretrix in the Gulf of Thailand. The lack of genetic structure in the Gulf of Thailand was also reported in populations of other marine species; for example, H. kuda (Panithanarak et al. 2010), Perna viridis (Prakoon et al. 2010), and Rachycentron canadum (Phinchongsakuldit et al. 2013).

\section{Implications for management of $M$. meretrix}

The genetic information of $M$. meretrix obtained in our study might facilitate fishery management. Our finding showed that the genetic structure has occurred between the Gulf of Thailand and the Andaman Sea. Thus, the management program to maintain genetic diversity should be treated as 2 separate conservation units because each population carries a unique genetic structure. For example, the increase of the abundance of $M$. meretrix population in the Gulf of Thailand via restocking should not be collected individuals from the Andaman Sea because it could lead to genetic contamination and outbreeding depression of natural populations. Interestingly, the $M$. meretrix population in the northern Gulf Thailand had a low genetic diversity, thus the management strategy in this region should be the focus. For instance, to enhance the genetic diversity of $M$. meretrix populations in the northern Gulf Thailand, the regulatory enforcement to capture and trade must be used to prevent population declines.

To conclude, in the present study, a total of 20 haplotypes from partial nucleotide sequences in the cytochrome oxidase subunit I gene were analyzed. A numerous of rare haplotypes indicating a large female effective population size of $M$. meretrix in Thailand. All populations, the haplotype diversity was high and the nucleotide diversity was low indicating that $M$. meretrix population expansion had undergone. The neutrality tests (Tajima's $D$ and Fu's $F s$ ) were negative values, indicating that the $M$. meretrix population had experienced population expansion. Besides that, a minimum spanning network interpreted a signature of sudden population expansion. The population genetic structure analysis could be separated $M$. meretrix into the Andaman Sea population and Gulf of Thailand population. The genetic structure of $M$. meretrix might be caused by gene flow disruption by the geographic barrier from Thai-Malaysian peninsular and larval behavior. Genetic information in our study is a proper way to construct effective sustainable management 
strategies to maintain and increase the genetic diversity of $M$. meretrix in Thailand.

\section{ACKNOWLEDGEMENTS}

This study was fully granted by Nakhon Si Thammarat Rajabhat University, Nakhon Si Thammarat, Thailand. We appreciate the support of local fishermen for their assistance to provide $M$. meretrix samples.

\section{REFERENCES}

Chu TJ, Wang D, Huang HL, Lin FJ, Tzeng TD. 2012. Population structure and historical demography of the whiskered velvet shrimp (Metapenaeopsis barbata) of China and Taiwan inferred from the mitochondrial control region. Zool Stud 51: 99-107.

Croos MDST, Pálsson S. 2010. Mitochondrial DNA variation and population genetic structure of white shrimp Fenneropenaeus indicus along the coastal belt of Sri Lanka. Aquat Living Resour 23: 315-323.

Donrung P, Tunkijjanukij S, Jarayabh P, Poompuang S. 2011. Spatial genetic structure of the Surf Clam Paphia undulata in Thailand waters. Zool Stud 50 (2): 211-219.

Excoffier L, Lischer HEL. 2010. Arlequin suite ver 3.5: A new series of programs to perform population genetics analysis under Linux and Windows. Mol Ecol Resour 10: 564-567.

Fernández-Pérez J, Froufe E, Nantón A, Gaspar MB, Méndez J. 2017. Genetic diversity and population genetic analysis of Donax vittatus (Mollusca: Bivalvia) and phylogeny of the genus with mitochondrial and nuclear markers. Est Coast Shelf Sci 197: 126-135.

Fishery Statistics Analysis and Research Group. 2017. Fisheries Statistics of Thailand, No. 5/2017. Department of Fisheries. Ministry of Agriculture and Cooperatives, Thailand. [Thai]

Fourdrilis S, de Frias Martins AM, Backeljau T. 2018. Relation between mitochondrial DNA hyperdiversity, mutation rate and mitochondrial genome evolution in Melarhaphe neritoides (Gastropoda: Littorinidae) and other Caenogastropoda. Sci Rep 8: 17964. DOI: $10.1038 / \mathrm{s} 41598-018-36428-7$

Fu FX. 1997. Statistical tests of neutrality of mutations against population growth, hitchhiking and background selection. Genetics 147: 915925.

Gilleard JS, Redman E. 2016. Chapter Two-Genetic diversity and population structure of Haemonchus contortus. Adv Parasitol 93: 3168.

Gu XF, Dong YH, Yao HH, Zhou XL, Qi XY, Lin ZH. 2015. Microsatellite marker analysis reveals the distinction between the north and south groups of hard clam (Meretrix meretrix) in China. Genet Mol Res 14 (1): 1210-1219.

Hamli H, Idris MH, Hena MKA, Rajee AH. 2019. Fisheries assessment, gametogenesis and culture practice of local bivalve: A review. Pertanika J Trop Agric Sci 42 (1): 103-124.

Johannesson K, Ring AK, Johannesson KB, Renborg E, Jonsson PR, Havenhand JN. 2018. Oceanographic barriers to gene fow promote genetic subdivision of the tunicate Ciona intestinalis in a North Sea archipelago. Mar Biol 165: 126. DOI: 10.1007/s00227-018-3388-x

Kumar S, Stecher G, Tamura K. 2016. MEGA7: Molecular evolutionary genetics analysis version 7.0 for bigger datasets. Mol Biol Evol 33 (7): 1870-1874.

Larkin MA, Blackshields G, Brown NP, Chenna R, McGettigan PA, McWilliam H, Valentin F, Wallace IM, Wilm A, Lopez R, Thompson JD, Gibson TJ, Higgins DG. 2007. Clustal W and Clustal X version 2.0. Bioinformatics 23 (21): 2947-2948.

Li HJ, Zhang JJ, Yuan XT, Zhang AG, Liu GZ, Shao KS, Wang L. 2016. Genetic diversity and differentiation of seven geographical populations of hard clam (Meretrix meretrix) assessed by COI and microsatellite markers. Acta Ecologica Sin 36: 499-507.

Ma C, Cheng Q, Zhang Q, Zhuang P, Zhao Y. 2010. Genetic variation of Coilia ectenes (Clupeiformes: Engraulidae) revealed by the complete cytochrome b sequences of mitochondrial DNA. J Exp Mar Biol Ecol 385:14-19.
Nei M. 1987. Molecular Evolutionary Genetics. Columbia University Press, New York.

Nei M, Tajima F. 1981. DNA polymorphism detectable by restriction endonucleases. Genetics 97: 145-163.

Neo ML, Todd PA. 2012. Population density and genetic structure of the giant clams Tridacna crocea and T. squamosa on Singapore's reefs. Aquat Biol 14: 265-275.

Omori R, Wu J. 2017. Tajima's D and site specific nucleotide frequency in a population during an infectious disease outbreak. Siam J Appl Math 77 (6): 2156-2171.

Panithanarak T, Karuwancharoen R, Na-Nakorn U, Nguyen TTT. 2010. Population genetics of the Spotted seahorse (Hippocampus kuda) in Thai waters: Implications for conservation. Zool Stud 49 (4): 564576.

Phinchongsakuldit J, Chaipakdee P, Collins JF, Jaroensutasinee M, Brookfield JFY. 2013. Population genetics of cobia (Rachycentron canadum) in the Gulf of Thailand and Andaman Sea: Fisheries management implications. Aquacult Int 21: 197-217.

Prakoon W, Tunkijjanukij S, Nguyen TTT, Na-Nakorn U. 2010. Spatial and temporal genetic variation of green mussel, Perna viridis in the Gulf of Thailand and implication for aquaculture. Mar Biotechnol 12: 506-515.

Ramirez-Soriano A, Ramos-Onsins SE, Rozas J, Calafell F, Navarro A. 2008. Statistical power analysis of neutrality tests under demographic expansions, contractions and bottlenecks with recombination. Genetics 179: 555-567.

Rosly HAM, Mohd-Nor SA, Yahya K, Naim DM. 2013. Mitochondrial DNA diversity of mud crab Scylla olivacea (Portunidae) in Peninsular Malaysia: a preliminary assessment. Mol Biol Rep 40 (11): 64076418.

Rozas J, Ferrer-Mata A, Sánchez-DelBarrio JC, Guirao-Rico S, Librado P, Ramos-Onsins SE, Sánchez-Gracia A. 2017. DnaSP 6: DNA Sequence Polymorphism Analysis of Large Datasets. Mol Biol Evol 34: 3299-3302.

Sienes RKA, Juranes RSJ, Metillo EB. 2018. Lunar periodicity in reproduction of two venerid clams Meretrix meretrix and Katelysia hiantina in Panguil Bay, Northern Mindanao, Philippines. Intl J Biosci 13 (6): 70-81.

Saramul S. 2017. Seasonal monsoon variations in surface currents in the Gulf of Thailand revealed by high-frequency radar. Eng J 21: 4. DOI: 10.4186/ej.2017.21.4.25

Slatkin M, Hudson RR. 1991. Pairwise comparisons of mitochondrial DNA sequences in stable and exponentially growing populations. Genetics 129: 555-562.

Suppapan J, Pechsiri J, O-Thong S, Vanichanon A, Sangthong P, Supmee V. 2017. Population genetic analysis of Oceanic paddle crab (Varuna litterata) in Thailand. Sains Malays 46 (12): 2251-2261.

Tajima F. 1989. Statistical method for testing the neutral mutation hypothesis by DNA polymorphism. Genetics 123: 585-595.

Trang VT, Quynh LT, Thiet CCC, Duc NH, Ha TTT. 2018. Genetic relationship of asiatic hard clam populations collected in northern coastal provinces in Vietnam based on mtDNA sequence analysis. J Aquac Mar Biol 7 (1): 00184. DOI: 10.15406/jamb.2018.07.00184

Wang C, Chen AH, Cao YW, Yang P, Zhang Y, Yao GX, Cai YX. 2016. Genetic relationship analysis of six Meretrix meretrix populations from different sea areas. Mar Fish 3: 262-272.

Wang IJ, Glor RE, Losos JB. 2013. Quantifying the roles of ecology and geography in spatial genetic divergence. Ecol Lett 16:175-182.

Wang X, Kong L, Chen J, Matsukuma A, Li K. 2017a. Phylogeography of bivalve Meretrix petechialis in the Northwestern Pacific indicated by mitochondrial and nuclear DNA data. PLoS ONE 12 (8): e0183221. DOI: 10.1371/journal.pone.0183221.

Wang W, Ma C, Chen W, Zhang H, Kang W, Ni Y. 2017b. Population Genetic diversity of Chinese sea bass (Lateolabrax maculatus) from southeast coastal regions of China based on mitochondrial COI gene sequences. Biochem Syst Ecol 71: 114-120.

Xue DX, Wang HY, Zhang T, Liu JX. 2014. Population genetic structure and demographic history of Atrina pectinata based on mitochondrial DNA and microsatellite markers. PLoS ONE 9 (4): e95436. DOI: 10.1371/journal.pone.0095436.

Zheng J, Nie H, Yang F, Yan X. 2019. Genetic variation and population structure of different geographical populations of Meretrix petechialis based on mitochondrial gene COI. J Genet 98: 68. DOI: 10.1007/s12041-019-1111-4. 